\title{
Knowing the Unknown through the Known: The Case for Indigenous Knowledge in Sustainable Development
}

\author{
Ajibade, Lanre Tajudeen
}

\begin{abstract}
This paper focused on the need to introduce new ideas through the existing ones. It used this to express the place of existing knowledge hereafter referred to as indigenous knowledge, in sustainable development. The paper proceeded from the understanding of the concept of indigenous knowledge, its relevance, to an inventory of empirical studies on indigenous knowledge as it relates to agricultural development. The paper concluded by recognizing the need to inculcate this understanding into African Youths so that it will improve their creativity for sustainable development. This becomes more important following Vilakazi (2002) who stressed that humanity emerged first in Africa and that Africa is the mother of humankind who prepared the remarkable cultural foundation for human development.
\end{abstract}

\section{Introduction}

Simply put, it is better to impact into people what is unknown through the known. This is the focus of this paper. In this way, man through his cognitive behaviour, will be able to relate the unknown to the known and therefore, identifies the differences, which makes adoption easy.

The known knowledge in this case is what is termed indigenous, local or traditional knowledge specifying how people do things themselves. The unknown knowledge on the other hand refers to any knowledge that is alien to the people. What quickly comes to mind is the invasion of the African environment with the western ideas without much consideration for the African's views or perspectives. 
This paper defines the term 'indigenous knowledge' along with associated concepts; its relevance and need. Further, the paper addresses empirical studies on indigenous knowledge and agricultural development, and provides a typical case study to identify its focus.

\section{The Concept of Indigenous Knowledge}

People in different places define indigenous knowledge in different ways, but all have the same focus. It is the local knowledge, which has been institutionalized, built upon and passed from one generation to the next (Odhianbo and Jahan, 1990; Osunade, 1992; Warren, 1992). According to Mishra (1989, it is built from and based on thousands of years of experience. However, Ngwasiri (1995) expresses that the term 'indigenous knowledge' has no universally accepted definition. Rather, it has many descriptions such as local knowledge, location and culture specific knowledge, traditional knowledge and localized knowledge systems, which are unique to a particular society or ethnic group. In practical terms, these are considered as the indigenous technologies developed by local community to solve particular problems taking cognizance of all the local relevant factors. In other words, it is at best used to distinguish between these knowledge systems developed by a community and the international knowledge system, which is generally referred to as western knowledge.

The works of Abrahams (1987); Oladimeji (1987); McNeehy (1989); Kater (1993); Munyakho (1994) and Sindiga (1995) buttress the fact that indigenous knowledge exists in all spheres of life such as education, engineering, health, politics, agriculture and even sports. In agriculture, the solutions to farmers' problems are developed by farmers themselves, the technology and knowledge is specific to the farm's environmental conditions and farmers' needs.

Following this same view, Pawluk, et al. (1992) consider indigenous knowledge as bodies of knowledge that develop as a certain culture or ethnic group strives to meet subsistence goals in a particular ecological setting. The tern 'culture' used here presupposes that indigenous is culture-based and the understanding that subsistence 
production is intuitively related to culture (Pawluk, et. al., 1992) makes it imperative to dwell into defining culture.

In defining culture, sociologists strive at the objective description of a people's social heritage (Oladimeji, 1987). Scientifically, it is often defined in blanket terms as the total way of life of a people (Otite and Ogionwo, 1981). According to Taylor (1972), culture is that complex whole, which includes knowledge, belief, arts, morals, law, custom and any other capabilities and habits acquired by man as a member of society. It is considered impersonal and this can be taken that every society has its own distinctive ways of doing things. This is particularly what makes people to consider other people's culture as 'prelogical' or irrational' and in so doing, have either dismissed or greatly played down its validity (Howes and Chambers, 1980).

Although, anthropologists use the adjective 'primitive' and 'traditional' to describe anything concerning African cultures, the more favoured word now is indigenous, which is less value laden. It connotes something, which belongs to a people. In this study, the term 'indigenous knowledge' is used to refer simply to the knowledge and know-how acquired by man through time and experience as a member of a society.

\section{Relevance and Need for Indigenous Knowledge}

In order to establish the relevance of indigenous knowledge in developmental efforts, several authors have given their observations in several studies. To this end, its relevance can best be appreciated through the presentation of the following examples. Howes and Chambers (1979) for instance, observed that indigenous knowledge can be used either to economize on the use of scarce trained scientific manpower, or to extend the range of observations upon which science can draw. To them, instances where this has happened are few, but suggest a considerable potential. 
According to Hoskins (1990), only few of the community projects initiated over the past decade have succeeded. Many of them have failed because of the disregard for local needs and priorities or the failure to involve local groups in the planning and implementation of local projects. Indigenous knowledge is particularly relevant in resource conservation according to Ajibade (1999) because indigenous societies have profound and detailed knowledge of the system and species with which they are in contact for generations. Buttressing this point, Richards (1979) affirms that many traditional beliefs and attitudes to environmental resources are oriented to conservation rather than exploitation. On this note, Ajibade (1999) submits that indigenous natural resource management techniques are not primitive, destructive or ineffective contrary to the belief of many policy makers and western scientists. They are considered as being sophisticated, scientifically valid, productive and appropriate. This fact is particularly true of indigenous knowledge for the amazing technological advances and organizational skills of homosapiens in the last three centuries, according to Baba (1994), gave the impression that man had won the context. This is however within his respective culture, if this is the case, and then man's views must be respected in any developmental efforts. Biggs and Clay (1981) in line with this, note that some of the most successful innovations in Asian agriculture have had their origin in the traditional knowledge. It is on this note that Richards (1989) suggests less emphasis on introduction of modern techniques to farmers but more emphasis on how to foster and support local adaptation and inventiveness. In order words, there is the need to start with what exists already.

In spite of the existence of the police force, whose primary duty is to protect citizens against possible evils, rate of crime has escalated in our urban centres. Many residents have therefore resulted to the use of vigilante groups to supplement the efforts of the state to curb crime. A good example of this is that of Sungusungu in Tanzania (Abrahams, 1987). This has been successful because its organization and operation have indigenous root. 
The relevance of indigenous knowledge is further buttressed in the work of Rene Reusen and Jan Johnson (1994) where emphasis is being placed on the need to link modern ideas with the traditional or local ideas. In their view, it is believed that for the development of artisanal fishing port, the government field officers who traditionally deal with document production, statistics, quarrels, licenses, taxes, etc., need to do more to support local initiatives. In other words, they need to have a truly detailed and systematic knowledge of the artisanal fishery ports of the local level particularly in the area of how people work, what the economic producers see as their most important problems and what they would like to do about them.

Bunch and Hopez (1995) identify local innovations as one of the factors which COSECHA (the Association of Advisors for a sustainable, ecological, and people-centred agriculture) sees as absolutely critical to the villagers becoming the subject of their own development.

Mishra (1989) witnessed the use of indigenous knowledge in curing certain diseases in North India. This, according to Pine, et.al. (1992), works more slowly but is more thorough and effective than westeren pharmacology. Modern science according to Mishra (1989) has confirmed the veracity of some indigenous knowledge. For instance, Cucurbit leaves have been found (at Iowa State University) to have some chemicals that help to lower cholesterol. The leaves of allium species (onion, garlic, etc.) have been found to prevent ulcer. Elizabeth Kafaru (Late), a onetime Columist in the Guardian, a Nigerian Daily Newspaper, has proved this. The Neem tree has also been found by the International Rice Research Institute (IRRI) to have certain chemicals with properties to serve as insecticides.

Even though today, the issue still generates controversial opinions, it is generally accepted by the scientific community of the world that the indigenous civilization of the American continent was not as savage as had been thought (Quintan, 1992). In fact, by 1492, many of these primitive indigenous societies were in advance of the European 
societies in many aspects he claims. There exist no records of famine occurring in the American continent before the sixteenth century because many indigenous civilizations in America had mastered crop production in a variety of different environments. For example, the Aztecs built agricultural raised beds in swamps; the Quechuas constructed terraces on the steep slopes of high mountains and remains of irrigation systems have been found in various areas; Nesco-America and Amazonian peoples produced crops in the tropical rainforest without destroying it.

The maintenance of the ecological balance and the productivity of the soil were probably restricted to the shifting cultivation systems and multicrop patterns used. Shifting cultivation is the alternate clearing and cropping of small and isolated patches of land in order to avoid soil exhaustion and the spreading of pests and diseases. Only land where the living population had reached its climax was cleared in order to follow nature's pattern of restoration. Multicrop on the other hand, is known to make a more efficient use of the soil fertility and to have a higher productivity per unit area. Such system protects the soil against erosion, furthers the development and production of associated crops, and helps to maintain a better balance between predators and pests.

Attempts by colonialists to change the attitudes of the Johya (the foundational pastoralists in India) towards practicing intensive cultivation through the construction of the Rajasthann Canal failed. Livestock remained their most important assets and animal husbandry, their primary occupation simply because pastoralism evolved there as a result of existing conditions, which shaped the social institution in their own interest and maintained control by diuscouraging the adoption of new ways of life (Sinha, 1996). Similarly, in spite of the construction of modern animal feeds factories and bore holes in Gidan Magagi Grazing Reserve of Northern Nigeria, the Fulanis still depend on free range grazing supplemented with crop residues and on the rains for drinking water for themselves and their animals for almost eight months of the year (Salih, 1992). 
Consequent upon the aforementioned examples, some insightful conclusions concerning areas of improvement according to Pawluk, et.al (1992) can be made and these include strategies that:

(a) are genuinely sensitive to the problems faced by farmers;

(b) invite farmers' participation and therefore, enhance the capacity of local people to solve their own problems;

(c) are based on a thorough understanding of the local environment and ecology.

All these generally reflect the need for a greater awareness on the part of the development planners of the situation, which they hope to improve. Indeed, the dynamic adaptive processes by which African farmers collect information, experiment and continually adjust their own technologies is a helpful starting point for research and development efforts (Yates, 1989). The established fact here is that the NGOs, farmers and agricultural researcher have very different knowledge systems and approaches to agriculture. As such, establishing linkages among them is essential to respond to the full range of issues concerning sustainable agricultural development.

In spite of the established importance of indigenous knowledge, appreciating its utility is however difficult for many development workers as they have to admit that they are not the experts; hence, the need to concentrate efforts towards its acceptability. The words of Lowenthal (1961) become more relevant here as they explicitly highlight the relevance of man's views in developmental efforts. He states that "all aspects of the environment exist for us only so far as they are related to our purposes. If you leave out human significance, you leave out all constancy, all respectability, all form". So, in any efforts geared towards human development, rather than throwing money carelessly at the problems of local small holder agricultural farmers, it is pertinent to understand its logic and build gradually on the established farming systems.

The above justification for revaluing indigenous knowledge does not in any way depend on an assumption that such knowledge is superior 
to modern knowledge. It is just that rural people know useful things, which other people do not know. That they are more likely to work a new technology they themselves have had a hand in devising, and that they have a good moral claim to participate in deciding their own future on the basis of their own experience.

\section{Empirical Studies on Indigenous Knowledge and Agricultural Development}

Academic concern with indigenous knowledge dates back, at least, as far as the first intensive fieldwork by anthropologists, but only in recent years has the possibility of using such knowledge as a basis for development activities been entertained (Howes, 1979). Some of the best pioneering works on indigenous knowledge at international level can be attributed to the efforts made by scholars like Michael Warren, Paul Richards, David Baker, Michael Howes, Osward Welner and a host of others. In Nigeria, they include J.S. Oguntoyinbo, A. Faniran, O. Areola, M.A.A. Osunade, David Atte, Oguntunji Titilola, L.T. Ajibade to mention but a few. Their efforts have been geared towards establishing the basis for the utility of indigenous knowledge in agricultural development. For instance, Warren, et.al.,(1989) wrote volumes of works on ethno-veterinary medicine, indigenous agricultural knowledge and gender issues. Richards (1079), Howes and Chambers (1980), Biggs and Clay (1981), Osunade (1987), Tabor (1993), Ajibade (2002) and several others have also emphasized the relevance of utilizing indigenous knowledge in soil resource inventory for increased agricultural production. Works have also been done on indigenous soil and water conservation in Africa. Examples of these include those of Kassogie, et.al. (1990), reig (1991) and Hagmann and Murwira (1996). The role of indigenous soil knowledge in agricultural development is exemplified in the work of Baker, et.al. (1977) and Pawluk, et.al (1992) using Ikale (Ondo State), Kabba (Kogi State) and Alayi (Imo State) in Nigeria as sampled areas, confirmed the high quality of farmers' environ mental knowledge in terms of relevance to the monitoring of agricultural resources. 
On documenting indigenous knowledge in relation to land evaluation in Nigeria, Warren (1992) presents a record of indigenous knowledge of soils and soil crop relationship in four ecological zones (Tropical Rain Forest, High Plateau, Savanna and the Inland Valley). Indigenous knowledge of soil properties and other factors believed to be important to crop production, control of soil erosion, and soil management was also recorded. Example is the work of Defoer and Kante (1994) on the methods used by farmers in the Minianka region of southern Mali, in classifying and managing their land. Osunade (1988) also carried out similar work in the southwestern Nigeria were he documented how small farmers identify crop soils in terms of suitability classification.

\section{Case Studies}

In an attempt to validate the ability of indigenous systems of land evaluation, Ajibade (2002) iden tified, recorded and classified farmers' local Knowledge of land evaluation in the Yoruba speaking area of Kwara State; studied the farmers' methods of evaluation; and compared this with the modern evaluation techniques. Using a multimethod approach (Baker, 1980) or integrated data acquisition technique (Laws and Luing, 1996), which involves participant observation, interviewing and questionnaire administration, the study observed the following:

1. That small farmers also evaluate their land except that the procedures differ. While the Farmers rest on the use of their sensory organs of sight, touch, feeling and smell right on the field, the modern procedure involves detailed laboratory analysis, which takes place outside the field. Now, it is a problem for the modern technique to be adopted easily because it requires a certain level of literacy, which is either lacking or low among African small farmers.

2. Despite the differences in procedures, a comparative study of farmers' identification and laboratory analysis reveal about $76 \%$ similarity. The farmers were made to provide the characteristics of the 
identified soils, samples of the same soils were subjected to laboratory analysis and great deal of similarities was observed

3. In the same vein, the comparison of small farmers' colour determination with that of the modern technique involving the use of Munsel Colour Chart was also done. Though, the colour names looked different from those of the small farmers', a consideration of "Human Value System" (Atteh, 1980) and a deep look into the colour name relationship reveal very great similarities. In fact, many of the soils described by the farmers fit within the concept of soil series and they have a wealth of information on these soils, including their relative productivity.

4. Above all, Osunade (1993) identified three essential requirements of land evaluation to include:

a. analysis of the requirements of individual concerned with land use (i.e. in terms of what the land is intended to be used for);

b. the delimitation of land in terms of geographical area (i.e. creation of land mapping units); and

c. ability to recognize a defined land unit in another area for predictive purposes.

Whereas, the small farmers' evaluation exercise considers the first two requirements, they do not find the third requirement easy simply because of the complexity in the nature of soil, which makes soil identification difficult sometimes, and the uncodified nature of their procedures. Therefore, small farmers in the study area are mainly concerned with just the land available to them. They do not put into consideration the possibility of relating what is obtainable in their area to other areas.

\section{Implications for Sustainable Development}

It is imperative at this juncture, to recognize the need to inculcate this understanding into African Youths so that it will improve their 
creativity for sustainable development. This paper believes that the youths must be confident and creative for the achievement of sustainable development. This they can achieve by re-discovering themselves within their own traditions, language, history and environment. This is in line with the thoughts of the group, which broadly has to do with the need to understand people's cultural roots in order to know why they do what they do.

It is noteworthy to stress that African societies have been corrupted through the so-called western civilization. Indeed, western civilization has substituted most African ideas such that our own ways of doing things are being abandoned. Unfortunately, there has not been adequate break-through because their introduction did not recognize what was in existence. Consequently, there has been moral decadence among our youths. This particularly calls for re-definition of our concern for our own traditional culture. Buttressing this submission, Vilakazi (2002) asserts that:

Healthy and genuine development policies in Africa must be founded upon the principle and pattern of African civilization. The greatest cause of distortion of African development policies is the fact that policy makers have crafted development policies for Africa out of the principles and patterns of western civilization. The triumph of the African Slave Trade, and conquest of Africa by the west, resulted in the rejection of the concept and historical validity of African civilization.

He therefore suggests that African intellectuals should engage in fieldwork on their own people, and on themselves, as part of a truly great efforts aimed at reconstructing Africa and preparing all of humanity for conquering the world for humanity. This should be based first and foremost, on the utilization of the resources provided by African civilization. This however, does not indicate that other people's ideas cannot be adopted. The fact is that it must not be allowed as substitutes to indigenous ideas. People know their local 
environment and must have developed means (unique to them) of solving various problems. Such ideas may complement the existing ideas for the attainment of a sustainable development in all spheres of human life.

\section{Conclusions and Recommendations}

The role of indigenous knowledge especially in providing the basis for a sustainable approach to development, which has been ignored for many decades, is now being recognized in many countries. While the move is appreciated, it is necessary to spread this to different cultural settings so that full documentation can be obtained at least on a regional level. This role has been identified through the ability of indigenous knowledge systems to reduce reliance on scarce-trained scientific manpower and extend the range of observations upon which science itself, can draw.

This paper concludes by stres\$ing the need to study and understand the existing systems in order to attain sustainable development in Africa. Based on such studies according to Okigbo (1991), the various underlying processes that made them sustainable can be identified and improved upon through research.

In addition to efforts toward strengthening the recognition of indigenous knowledge systems in Africa, attempt should be made to encourage indigenous means through which technical knowledge can be created, accumulated and stored in a database where it can be retrieved for manipulation and usage in decision making. For instance, the overwhelming bulk of technical change, which impinges on relatively, deprived and rurally located groups in the Third World occur through linkage B (See figure 1). This is linked back to processes of creating, manipulating and using technical knowledge, which are exogenous to such groups. Both linkages $\mathrm{A}$ and $\mathrm{C}$ according to Bell (1979), are weak or non-existent so that indigenous capabilities play only a marginal role in effecting technical change. 
The scientific means through which this aforementioned recommendation can be made now is what is termed Geographical Information Systems (GIS). This brings us back to the focus of the paper - that the use of GIS in all aspects of knowledge may not be easy to absorb and understood without the understanding of our own methods.

This paper must not fail to remind Africans that we should not be deceived by any imported ideas. This is because humanity emerged first in Africa and according to Vilakazi (2002), Africa is the mother of humankind. She prepared the remarkable cultural foundation, which some of her children took along with them as they left for other regions and corners of the world.

\section{References}

Abrahams, R. (1987), "Sungusungu, Village Vigilante Groups in Tanzania”, African Affairs. The Journal of the Royal African Society, 86(343):179-196.

Ajibade, L.T. (2002), Indigenous Systems of Land Evaluation in the Yoruba Speaking Part of Kwara State, Unpublished Ph.D Thesis, Obafemi Awolowo University, Ile-Ife, Osun State, Nigeria

Ajibade, L.T. (1999), "Indigenous Approach to the Control of Soil Erosion among Small Scale Farmers in Asa Local Government Area, Kwara State, Nigeria, The Nigeria Journal of Agriculture and Rural Management (JARM), 5(1):20-29.

Baba, J.N. (1994), "Sustainable Development and the Nigerian Environment", The Nigerian Geographical Journal, 1:1-19.

Barker, D., Oguntoyinbo, J. and Richards, P. (1977), The Utility of the Nigerian Peasant Farmers knowledge in the Monitoring of Agricultural Resources. Monitoring and Assessment Research Centre, The scientific committee on problems of the environment, International council of scientific unions, Report No. 4, pp. 4-26.

Biggs, S.D. and Clay, E.J. (1981), "Source of Innovation in Agricultural Technology", World Development, 9.

Bell, M. (1979), "The Explitation of Indigenous Knowledge: Whose Use of What for What?" IDS Buletin, 10(10):44-50.

Bunch, R. and Hopez, G. (1995), Soil Recuperation in Central America: Sustaining Innovation after Intervention, Gatekeeper Series, 55 SAP, International Institute for Environment and Development, London. 
Hagnann, J. and Murwiwa, K. (1996), Omdogempis Soil and Water Conservation in Southern Zimbabwe: A Study of Techniques, Historical Changes and Recent Development under Participatory Research and Extension".

Hoskin, M. (1990), "Trees for the People”, CIKARD News, 2(1): 14-15).

Howes, M. (1979), "The Uses of Indigenous Knowledge in Development", IDS Bulletin, 10(2): 8-10.

Howes, M. and Chambers, R. (1980), "Indigenous Technical Knowledge: Analysis, Implications and Issues.” In: Brokensha, D.W., Warren, D.M., and Wener, O. (1980), Indigenous Knowledge System and development, University Press of America, USA.

Kante, S. and Dofoer, T. (1994), "How Farmers Classify and Manage their Lands: Implications for Research and Development Activities", DNP Issue Paper, 51, IIED.

Kassogue, A., Dolo, J. and Ponsioen, T. (1990), "Traditional Soil and Water Conservation on the Digon Plateau, Mali", DNP Issue Paper, 23, IIED.

Lowenthal, D. (1961) "Geography, Experience, and Imagination: Towards a Geographical Epistemology", Annals of the Association of American Geographers, 51.

McNeely, J.A. (1989) "Indigenous Knowledge in the Development Process: Policy and Practice of IUCM", CIKARD NEWS, 10(2), Iowa State Univ., Ames.

Mishra, K.N. (1989). "Growing Up With Indigenous Knowledge in North India", CIKARD News, 2(2): 2-3.

Munyakho, D. (1994). "Taking Rural Traditions into Account". African Farmer, 13, Newyork.

Ngwasiri, D.N. (1995). "Knowledge is of Two Kinds". SPORE, CTA Bulletin.

Odhiambo, T. and Johan Ran Kamp (1990). "You Cannot Fix Indigenous Knowledge". ILEIA Newsletter

Oladimeji, I.A. (1987). "Indigenous Conception, Work Attitudes and Natural Development in Nigeria". Research For Development, NISER, 4(1 \& 2).

Okigbo, B.N. (1991), Development of Sustainable Agricultural Production Systems in Africa: Roles of International Agricultural Research Centres and National Agricultural Research Systems, Ibadan: IITA.

Osunade, M.A.A. (1987) "A Viable Method of Land Capability Classification for Small Farmers." Journal of Environmental Management, 25.

Osunade, M.A.A. (1988). "Soil Suitability Classification by Small Farmers." The Professional Geographer, 40(2).

Osunade, M.A.A. (1992). "Identification of Crop Soils by Small Farmers of SouthWestern Nigeria". Environmental Management, 35.

Osunade, M.A.A. (1993). "Modern and Indigenous Land Evaluation Approaches in Swaziland." International Journal of Environmental Studies, 43. 
Pawluk, R.R., Sandor, J.A. (1992). "The Role of Indigenous Knowledge in Agricultural Development." Journal of Soil \& Water Conservation, 47(4).

Pine, D., Wood, B., Wakegijig, R., Yelowhead, J. O., Harper, V., Harper, P. and Manitowabi, E. (1992). The Role of Indigenous Voice, INIPA, 1(5 \& 6).

Quintana, J. (1992), Thoughts on the Next 500 Years, The Indigenous Voice, Information Network of the Indigenous People of the Americas, (INIPA) 1(3).

Reij, C. (1991). "Indigenous Soil and Water Conservation in Africa." Gatkeeper Series, 27, IIED, London.

Rene Reusen and Jan Johnson (1994). "Linking Government Agents and Local Users: FUA for Artsanal Fishing Port Development." Special Issue on Participatory Tools and Methods in urban Areas, RRA Notes, 21, IIED, London.

Richards, P. (1979). "Community Environmental Knowledge in African Rural Development." IDS Bulletin, 10 (2).

Richards, P. (1989). Indigenous Agricultural Revolution and Food Production in West Africa, Hutchinson and Company, London.

Salih, M.A.N. (1992). "Pastoralists and Planners: Local Knowledge \& Resource Management in Gidan Magajia Grazing Reserve, Northern Nigeria." DNP News Paper, 33.

Sindiga, I. (1995). "Indigenous Knowledge and Gender - Differentiated Health Care Programmes in Kenya." IKDM, 3, Issue 1.

Sinha, S. (1996). "Resisting Change? : Adaptation by traditional Pastoralist to the Ragasthan Canal Project." DNP Issue Paper, 62.

Tabor, J.A. (1993). "Soil Survey and Indigenous Soil classification." Indigenous Knowledge \& Development Monitor, 1:(1).

Taylor, E.B. (1972). Primitive Culture. Longman, John Murray.

Vilakazi, H.W. (2002). "African Indigenous Knowledge and Development Policy." INDILINGA, 1:1-5

Warren, D.M., Slikkerveer, L.J., Titilola, S.O. (ed.) (1989). "Indigenous Knowledge Systems: Implications for Agricultural and International Development." Monograph. No. 11. The Technological and Social Change Programme, Iowa State University, USA.

Warren, D.M. (1992). "A Preliminary Analysis of Indigenous soil Classification and Management Systems in Four Ecozones of Nigeria.” NISER, Nigeria.

Yates, M. (1989) "Nigerian Farmers Ply Indigenous Research Approaches." CIKARD News, 1: (2). 


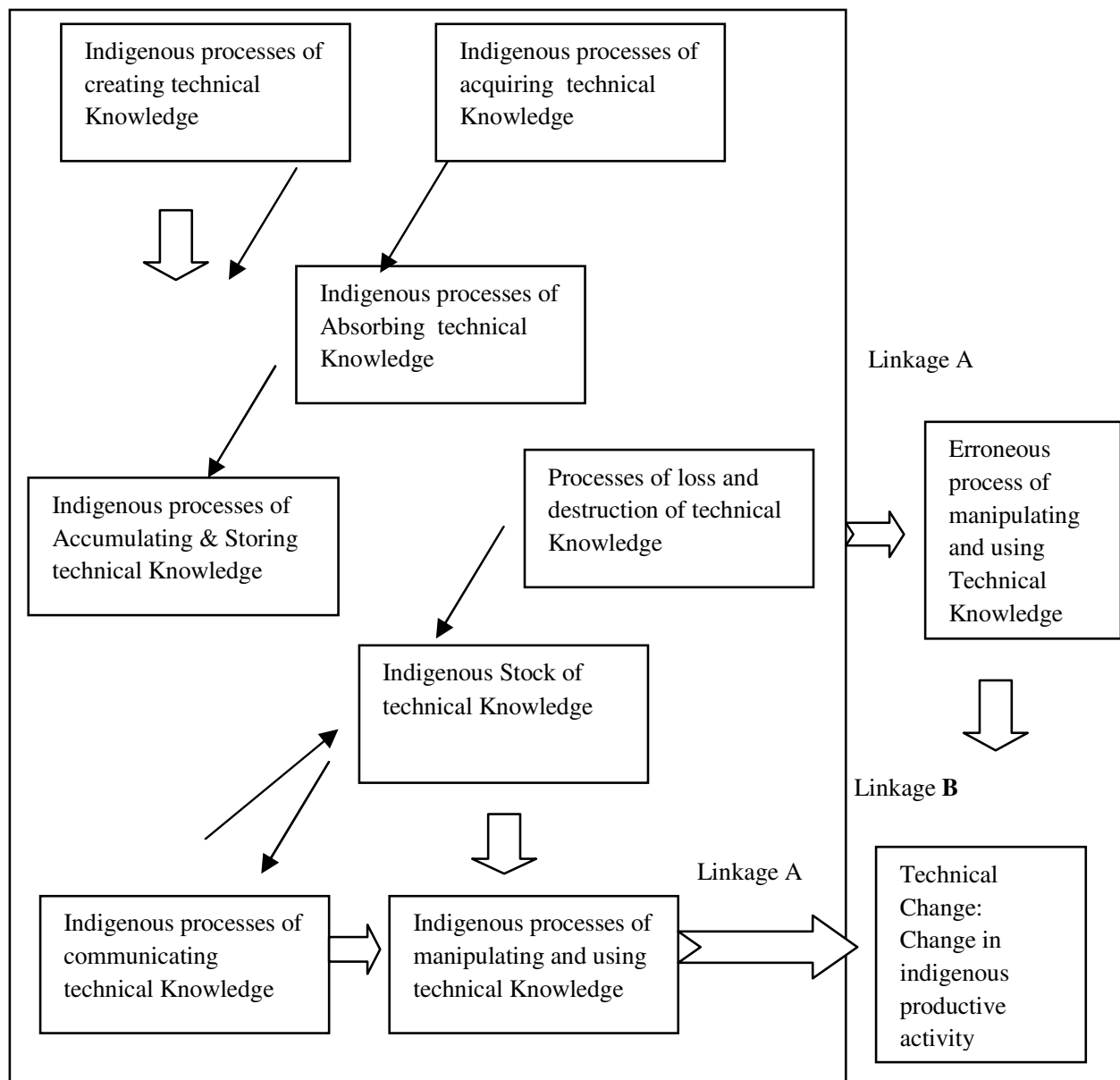

